\title{
PROTEÇÃO SOCIAL NO CONE SUL DA AMÉRICA LATINA NO SÉCULO 21: Entre o Seguro e a Assistência Social
}

\author{
http://dx.doi.org/10.21527/2176-6622.2020.54.154-164
}

Recebido em: 7/9/2020

Aceito em: 19/9/2020

\section{Lislei Teresinha Preuss}

Doutora em Serviço Social pela Pontifícia Universidade Católica do Rio Grande do Sul (2011). Mestre em Serviço Social pela Universidade Federal de Santa Catarina (2007). Graduada em Serviço Social pela Universidade Federal de Santa Catarina (1998) e em Pedagogia pela Universidade do Estado de Santa Catarina (1996). Professora-adjunta da Universidade Estadual de Ponta Grossa e do Programa de Pós-Graduação Interdisciplinar em Ciências Sociais Aplicadas. Tem experiência na área de Serviço Social, com ênfase em Serviço Social da Saúde, atuando principalmente nos seguintes temas: proteção social, política social de saúde, política social de saúde na América Latina, atenção primária à saúde. http://lattes.cnpq.br/3788365740475306. https://orcid.org/00000001-5786-7228. lisleipreuss@hotmail.com

\section{Nayara Cristina Bueno}

Doutoranda em Ciências Sociais Aplicadas na Universidade Estadual de Ponta-Grossa. Mestre em Serviço Social e Política Social pela Universidade Estadual de Londrina (2013). Graduada em Serviço Social pela Universidade Estadual do Centro-Oeste (2010). Professora do curso de Serviço Social da Universidade Estadual do Centro-Oeste. Atua principalmente nos seguintes temas: Proteção Social, Seguridade Social, Gestão Social, Assistência Social, Família e Políticas Públicas. http://lattes.cnpq.br/9913656499504352. https://orcid.org/0000-0003-2113-0931. nbueno@unicentro.br

\section{RESUMO}

A proteção social nas sociedades capitalistas periféricas possui particularidades relacionadas às marcas do colonialismo que dificultam o desenvolvimento de políticas sociais universais e na perspectiva dos direitos sociais. Com objetivo de apresentar um panorama da proteção social no Cone Sul da América Latina no século 21 foi realizada uma pesquisa exploratória que contou com revisão bibliográfica e análise estatística sobre o tema na base de dados da Comissão Econômica para a América Latina e o Caribe (Cepal). Após a apresentação de como o colonialismo mostra-se presente nas sociedades dessa região, os sistemas de proteção social contributivos e não contributivos são problematizados na sua relação com o mercado de trabalho, instável, informal e com condições precárias para os/as trabalhadores/as. Nas considerações finais identifica-se que os benefícios e programas existentes são resultado de lutas e mobilizações sociais e podem contribuir para a diminuição da pobreza e desigualdade social na região se combinados com políticas estruturais.

Palavras-chave: Colonialismo. Seguridade social. Políticas sociais.

\section{SOCIAL PROTECTION IN THE SOUTH CONE OF LATIN AMERICA IN THE 21 CENTURY:} BETWEEN INSURANCE AND SOCIAL ASSISTANCE

\section{ABSTRACT}

Social protection in peripheral capitalist societies has particularities related to the marks of colonialism that hinder the development of universal social policies and from the perspective of social rights. In order to present an overview of social protection in the southern cone of Latin America in the 21st century, an exploratory research was carried out that included a bibliographic review and statistical analysis on the subject in the database of the Economic Commission for Latin America and the Caribbean (Cepal). After presenting how colonialism is still present in societies in the region, contributory and non-contributory social protection systems are problematized in their relationship with the labor market, which is unstable, informal and with precarious conditions for workers. In the final considerations, it is identified that the existing benefits and programs are the result of social struggles and mobilizations and can contribute to the reduction of poverty and social inequality in the region if combined with structural policies.

Keywords: Colonialism. Social security. Social politics.

\section{SUMÁRIO}

1 Introdução. 2 Proteção social na América Latina e as marcas do colonialismo. 3 A centralidade do sistema contributivo nos países do Cone Sul da América Latina. 40 sistema não contributivo: focalização na pobreza. 5 Considerações finais. 6 Referências. 


\section{INTRODUÇÃO}

A proteção social nas sociedades capitalistas periféricas possuem particularidades relacionadas à forma como os países se inserem no mercado mundial, na condição de exportadores de matérias-primas, porque isso impacta no acesso e nas condições de trabalho e na renda. As marcas do colonialismo nas sociedades contribuem para a perpetuação das desigualdades econômicas, sociais e políticas, assim como se manifestam nas hierarquias sociais de classe, raça/etnia, gênero.

A proteção social pública, via políticas sociais, interfere nas atribuições das demais esferas de proteção social, quais sejam: a família, o mercado e a sociedade. É nessa relação, dinâmica e contraditória, que as necessidades sociais são atendidas, quanto maior a participação estatal, menor a sobrecarga da família (e das mulheres) e menos mercadorizadas e dependentes de ações filantrópicas estão as pessoas.

Este trabalho tem como objetivo apresentar um panorama da proteção social pública no Cone Sul da América Latina no século 21. Para isso foi realizada uma pesquisa exploratória que contou com revisão bibliográfica e análise estatística em duas bases de dados da Comissão Econômica para a América Latina e o Caribe (Cepal).

Na Base de Dados e Publicações Estatísticas (Cepalstat) foram coletadas informações sobre a situação de pobreza, extrema pobreza e índice Gini dos países do Cone Sul da América Latina: Argentina, Brasil, Chile, Paraguai e Uruguai, disponíveis ao público na Internet. As informações foram organizadas no Quadro 2.

Sobre os programas de transferência condicionada de renda e benefícios não contributivos os dados foram coletados na Base de Dados de Programas de Proteção Social não Contributiva na América Latina e Caribe, também disponível ao público na Internet. As informações foram organizadas nos Quadros 3 e 4 e apresentam as características de público-alvo, valor do benefício e cobertura de cada programa e benefício.

O trabalho está organizado em três momentos. Inicia-se com a discussão sobre as marcas do colonialismo na proteção social, demonstrando os limites da transposição de modelos europeus para a região devido às suas particularidades históricas, ligados ao passado colonial, mas também à diversidade das sociedades. Em seguida são problematizados os sistemas contributivos e não contributivos, separadamente apenas para fins didáticos, uma vez que compreende-se que eles estão relacionados e devem ser pensados de forma integrada.

Por fim, as considerações finais apontam que a redistribuição da riqueza socialmente produzida por meio da valorização do salário mínimo e dos benefícios sociais é um dos mecanismos que podem contribuir com a redução da pobreza e da desigualdade social na região, mas precisa estar combinada com reformas estruturais como a forma de arrecadação estatal.

\section{PROTEÇÃO SOCIAL NA AMÉRICA LATINA E AS MARCAS DO COLONIALISMO}

A revisão histórica sobre a inserção dos países da América Latina no mercado mundial não é apenas um pano de fundo no qual se desenvolvem os estudos sobre a região. Apresenta-se como uma exigência para compreender as sociedades latino-americanas na atualidade, tanto pelos problemas estruturais de desigualdade econômica, social e de acesso à política quanto pelas dificuldades em desenvolver políticas de proteção social rompendo com modelos eurocentrados.

A particularidade da região está, justamente, no fato de ser una e diversa. Para Rouquié (1982, p. 25) "a heterogeneidade interna marcha ao lado da homogeneidade externa, isto é, a diversidade das sociedades se inscrevem em um fundo comum do constrangimento da dominação internacional e a situação periférica". Esse conjunto de países estão na periferia do mercado mundial, enquanto exportadores de matérias-primas e fornecedores de mão de obra superexplorada, portanto possuem o seu desenvolvimento moldado pelo exterior.

Segundo Quijano (2005), no processo de colonialismo, a ideia de raça e divisão do trabalho serão associados e fortalecidos mutuamente. A ideia de raça irá diferenciar os conquistadores e os conquistados e será relacionada com estrutura biológica e fenótipo e, ainda, irá colocar os não europeus, em especial os índios americanos e os africanos na posição de inferioridade, relacionando-os ao primitivo, ao não civilizado. 
Isso favorece a divisão e a exploração do trabalho por meio do controle da produção, apropriação e distribuição dos produtos. Neste processo, organiza-se uma forma de trabalho que explora o trabalho dos índios e, posteriormente, dos escravos africanos, em um relação não mercantil, não paga, não assalariada e sustentada na ideia de raças inferiores. Desde o começo, portanto, há uma associação entre branquitude social e salário e, também, com os postos de mando da administração colonial (QUIJANO, 2005).

Sem nenhum interesse nacional, a burguesia latino-americana nasce voltada a atender aos interesses dos pares europeus (e, mais tarde, do capital financeiro internacional), posicionando-se contrária à democratização social e política, ou ainda, à construção de sociedades que respeitem os modos de vida, a cultura, a língua, as crenças, os territórios dos povos originários.

Conforme demonstra Quijano (2005), o processo de homogeneização da população, considerado necessário à constituição de um Estado moderno à europeia, levou ao extermínio dos povos originários nos países do Cone Sul da América, em especial na Argentina, no Chile e no Uruguai e, ainda, a imposição de uma ideologia da "democracia racial" que mascara o preconceito com índios e negros no Brasil.

Lugones (2014) também realiza importantes contribuições para compreensão do movimento colonial ao apontar que, além da inseparabilidade da raça e da exploração capitalista, a colonização realizou um processo de redução das pessoas, ao tornar o/a colonizado/a menos que seres humanos, destacando a consequência desse processo na vida das mulheres e no controle da sexualidade.

Estão postos alguns dos elementos que contribuem para explicar, por exemplo, o entendimento de que uma sociedade capitalista moderna ${ }^{1}$ deveria se assemelhar à sociedade europeia, realizando um processo de modernização linear, de transição agrária para a urbana e industrial, desconsiderando, assim, a realidade local, em que coexistem várias formas de organização do trabalho - trabalho coletivo, trabalho mercantil, trabalho escravo - não apenas o agrário e, mesmo esse, não se assemelha ao feudal.

Desconsiderando, também, as necessidades sociais da população que precisam ser atendidas, a proteção social, como organização social voltada para o atendimento das necessidades humanas básicas, é anterior ao capitalismo, uma vez que as comunidades e as famílias sempre se voltaram a garantir a vida e o bem-estar de seus membros. No capitalismo, contudo, isso se transforma substantivamente devido às mudanças do modo de vida, e o Estado e o mercado são instituições que passam a interferir e direcionar a forma como a proteção social é garantida.

Se a burguesia latino-americana nunca esteve voltada às necessidades nacionais, tem se valido do Estado para manter a histórica-estrutural-dependência, assim como as desigualdades econômicas, sociais e políticas internas. Isso se dá porque o Estado desenvolverá um papel peculiar nas sociedades latino-americanas, tanto que Rouquié (1982) afirma que foi o Estado colonial que contribuiu para erigir e estabelecer os grupos sociais dominantes mediante a distribuição de terras, de créditos e das políticas de trabalho voltadas à imigração.

Compreende-se que as políticas sociais desenvolvidas pelos Estados capitalistas são respostas às expressões da questão social, resultado da organização social capitalista, fundada na apropriação privada da riqueza socialmente produzida. Na América Latina a questão social tem seu cerne na colonização, expressa na violência, estupros, controle da reprodução, exploração do trabalho, desapropriação das terras, assassinatos, apropriação das riquezas naturais que geraram resistência e lutas sociais, as quais foram (e ainda são, em parte) respondidas com repressão e violência.

\footnotetext{
"Se o conceito de modernidade refere-se única ou fundamentalmente às idéias de novidade, do avançado, do racional-científico, laico, secular, que são as idéias e experiências normalmente associadas a esse conceito, não cabe dúvida de que é necessário admitir que é um fenômeno possível em todas as culturas e em todas as épocas históricas. Com todas as suas respectivas particularidades e diferenças, todas as chamadas altas culturas (China, Índia, Egito, Grécia, Maia-Asteca, Tauantinsuio) anteriores ao atual sistemamundo, mostram inequivocamente os sinais dessa modernidade, incluído o racional científico, a secularização do pensamento, etc." (QUIJANO, 2005, p. 231).
} 
Nesta região, a questão social está indissociável da questão étnico-racial e de gênero, uma vez que as mulheres negras e indígenas são as mais pobres, pois, quando se inserem no mercado de trabalho, lhes são atribuídas socialmente posições no mercado informal, desprotegido, mal-pago, em condições precárias. Às mulheres cabe ainda, predominantemente, o trabalho doméstico e de cuidados, ocasionando dupla e tripla jornada.

O racismo estrutural, conforme apresenta Almeida (2019, p. 50-51), decorre do modo como "se constituem as relações políticas, econômicas e jurídicas e até familiares". O racismo, na condição de "processo histórico e político, cria as condições sociais para que, direta ou indiretamente, grupos racialmente identificados sejam discriminados de forma sistemática."

Os sistemas públicos de proteção social reproduzem esse movimento ao elegerem os trabalhadores urbanos industriais e os funcionários públicos (imigrantes, homens, brancos) como os primeiros a serem protegidos pelo Estado, associados ao movimento de incentivo à urbanização e à industrialização com substituição de importações, no contexto do Estado desenvolvimentista do século 20, em especial entre os anos 1920-1980.

O trabalho assalariado estava voltado aos imigrantes, especialmente europeus. Enquanto os escravos, a exemplo do Brasil, permaneceram sem políticas indenizatórias, os imigrantes que foram trabalhar no setor agrícola receberam incentivos dos governos e aqueles que foram para os centros urbanos tiveram acesso privilegiado ao trabalho assalariado e protegido. Essas primeiras medidas públicas de proteção social tinham caráter contributivo, baseadas nas ideias bismarkianas de seguro social, ${ }^{2}$ advindas do modelo europeu.

No final do século 20 , desde os anos 80 , se generalizam as políticas de proteção social. Isso se dá no contexto de orientação econômica e política neoliberal, a partir do Consenso de Washington. Segundo Draibe e Riesco (2011), as características da proteção social, a partir desse período, são: a provisão mercantil de bens e serviços, a expansão de programas focalizados nos mais pobres, as redes sociais de proteção mínima, os programas de transferência de renda e a crescente expansão das Organizações Não Governamentais - ONGs.

A agenda principal será o combate à pobreza, contudo a pobreza no neoliberalismo é entendida como "responsabilidade individual ou coletiva dos setores por ela atingidos", como "fenômenos naturais ou produzidos pelo comportamento dos sujeitos que os padecem." Seu enfrentamento será focalizado, precarizado, passível de clientelismo, quando não realizado por instituições mercantis ou pela sociedade civil organizada (MONTAÑO, 2012, p. 3).

Ao desvincular a discussão da pobreza da histórica-estrutural-dependência dos países do Cone Sul da América Latina são reproduzidas, institucionalmente, as desigualdades econômica, social e política, tendo as políticas de proteção social mantido privilégios e penalizado os mais pobres.

Compreende-se que reformas estruturais como, por exemplo, modificar a forma de arrecadação estatal (taxando as propriedades e grandes fortunas em vez dos salários e do consumo), investir em políticas afirmativas e de proteção social universal, em detrimento do pagamento da dívida externa e rediscutir as prioridades do processo de desenvolvimento e a sociedade que queremos viver, são questões urgentes em vários países.

Ao ingressar no século 21, decorrente deste processo perpetuador de desigualdades, ocorrem mudanças consideráveis nos sistemas de proteção social. Os avanços sociais são instituídos em vários países, em especial durante o giro à esquerda no Cone Sul (2002-2018). ${ }^{3}$ Não foram suficientes, contudo, para romper com o projeto econômico e político neoliberal, por isso a expressão liberalismo de esquerda marca as primeiras duas décadas.

Diante disso, a proteção social permanece tendo como base a organização social do trabalho, com centralidade no sistema contributivo, enquanto que os programas de benefícios de caráter não contributivo estão sendo desenvolvidos de forma focalizada na população em situação de pobreza, como demonstrado nas próximas seções.

\footnotetext{
O seguro social surgiu na Alemanha impulsionado pelo chanceler Otto von Bismarck entre 1883 e 1889, que estabeleceu a proteção dos trabalhadores contra os riscos sociais da idade, invalidez e da doença, com obrigatoriedade de contribuição de trabalhadores e empregados e regulado pelo Estado (MESA-LAGO, 2006).

3 Na Argentina: Cristina Kirchner (2007-2015); no Brasil: Luiz Inácio Lula da Silva (2003-2010) e Dilma Rousseff (2011-2016); no Chile: Bachelet (2006-2010); no Paraguai: Fernando Lugo (2008-2012); e, no Uruguai: Pepe Mujica (2005-2010) e Tabaré Vázquez (2005-2020)
} 


\section{Debate}

\section{A CENTRALIDADE DO SISTEMA CONTRIBUTIVO NOS PAÍSES DO CONE SUL DA AMÉRICA LATINA}

Nos marcos do desenvolvimento do capitalismo nos países do Cone Sul da América Latina no século 20, a partir dos anos 20 , correlacionados ao processo de industrialização e urbanização, começam a ser postas em prática as primeiras medidas de proteção social pública, vinculadas à organização social do trabalho, em especial na Argentina, Brasil, Chile e Uruguai, enquanto o Paraguai iniciará somente na década de 40 (MESA-LAGO, 2006).

As primeiras medidas de seguro social tinham como característica privilegiar a extensão dos riscos cobertos, mais do que a extensão da população atendida. Além disso, estava voltada aos setores mais organizados da classe trabalhadora que possuíam poder de pressão sobre o Estado, em especial os setores econômicos estratégicos e aqueles de interesse do Estado de cooptação, neutralização e controle por meio dos benefícios sociais, como os servidores civis, professores e militares (MESA-LAGO, 2006).

Silva (2008) demonstra o papel dos grupos classistas e setoriais organizados nas reivindicações de políticas de seguro social, levando para a arena política as necessidades sociais e o Estado desenvolvendo um papel ativo nas respostas seletivas. Consequência deste processo é que as categorias menos organizadas, como os trabalhadores autônomos, trabalhadores rurais e trabalhadores domésticos foram os últimos a serem incorporados ao sistema. $\mathrm{O}$ atendimento seletivo dificultou o entendimento dos benefícios sociais como direito social, os quais, historicamente, foram percebidos como privilégio de algumas categorias.

O seguro social, como uma segurança ofertada àqueles que contribuem de forma obrigatória ao ingressar no mercado formal ou, mais tarde, de forma facultativa, garantem, por exemplo, os regimes de pensão, licenças remuneradas, seguros saúde e desemprego, de forma proporcional à contribuição efetuada.

Segundo Boschetti (2009), historicamente, ter um contrato de trabalho sempre foi condição ao acesso à seguridade social, por isso a universalização do acesso pressupõe a universalização do direito ao trabalho. 0 modelo vigente tem sido o europeu, desenvolvido no período entreguerras (entre as décadas de 40-70), permanecendo com maiores ou menores modificações.

A configuração da seguridade social se dará de forma diferenciada nos países, conforme as concepções adotadas pelas sociedades. A expressão foi usada pela primeira vez nos Estados Unidos em 1935, contudo vinculado à ideia de seguro social. O conceito de seguridade social como direito social que envolve os seguros sociais, a assistência social e os seguros voluntários complementares foi desenvolvido pelo inglês William Beveridge em 1942 (MESA-LAGO, 2006).

A seguridade social pode abranger o seguro social ou previdenciário e/ou de saúde (exemplo da Argentina, do Chile, do Uruguai e do Paraguai) e, ainda, incluir outras políticas de natureza não contributiva como o direito à saúde com caráter universal e a assistência social com características de seletividade (exemplo do Brasil).

Esse formato de proteção social, entretanto, tem sido, historicamente, excludente na América Latina, devido à instabilidade do mercado de trabalho e alto índice de informalidade, que chega à metade da população, além do desemprego e dos trabalhos precários. Além disso, gera desigualdades entre os trabalhadores, principalmente entre os funcionários públicos e privados, militares e trabalhadores de áreas urbanas e rurais.

Outros indicadores apontam para as desigualdades também entre os/as trabalhadores/as: os homens, de maior renda e com maior escolaridade são os que mais contribuem para os sistemas de seguro social. A participação feminina no trabalho formal é de $56 \%$, enquanto a dos homens é de $83 \%$ na região, por isso, no Chile e no Brasil, por exemplo, uma proporção significativa das mulheres acessam aposentadoria de forma indireta (pensão dos cônjuges) (OECD, 2015).

A maioria das mulheres precisa conciliar o trabalho remunerado com o trabalho doméstico e de cuidados, por isso inserem-se no mercado de trabalho informal, desprotegido, com baixa remuneração, o que repercute no acesso aos sistemas de seguro social. Destaca-se que a contribuição econômica do trabalho não remunerado realizado nos domicílios equivale a entre $15,2 \%$ e $24,2 \%$ do PIB da região, cifra que é superior a muitas atividades econômicas de vários países (CEPAL, 2019). 
A situação dos autônomos também é de fragilidades, uma vez que a estimativa é que apenas 17 a cada cem profissionais contribuem para os sistemas de seguro social, enquanto que esse número para assalariados é de 64 a cada cem. Ademais, somente entre $20 \%$ e $40 \%$ dos trabalhadores de menor renda contribuem e, quando combinado com a escolaridade esse número é ainda menor, por exemplo, no Paraguai, menos de $5 \%$ dos trabalhadores com menor escolaridade possui emprego formal (OECD, 2015).

A cobertura do seguro social/previdenciário nos países da América Latina e Caribe varia conforme o

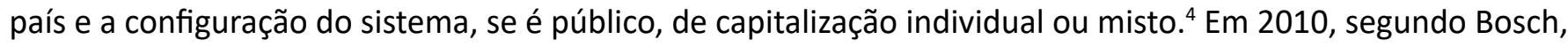
Melguizo e Pagés (2013), a média de cobertura era é $44,7 \%$ da população. Os autores exemplificam a baixa cobertura com a situação dos idosos, a cada cem idosos, apenas 40 recebiam aposentadoria por contribuição, 20 recebiam aposentadoria não contributiva e 40 precisam continuar trabalhando e/ou dependiam das famílias e da comunidade para sobreviver.

O Quadro 1 apresenta informações dos países do Cone Sul sobre a cobertura do seguro social/previdenciário no ano de 2018:

Quadro 1 - Cobertura Seguro Social/Previdenciário no Cone Sul da América Latina em $2018^{5}$

\begin{tabular}{|c|c|c|c|c|c|}
\hline País & Argentina & Brasil & Chile & Uruguai & Paraguai \\
\hline Cobertura Seguro Social/ Previdência Social & $51,0 \%$ & $63,5 \%$ & $70 \%$ & $71 \%$ & $22,8 \%$ \\
\hline
\end{tabular}

Fonte: Argentina: OECD (2015); Brasil: IBGE (2020); Uruguai e Chile: CEPAL (2019); Paraguai: MTESS (2018).

O Paraguai tem a menor cobertura previdenciária do Cone Sul, apresenta diversidade na forma de filiação devido à existência de vários institutos de seguro social, o que causa diferenças entre as contribuições e benefícios; a cobertura entre funcionários públicos é maior, comparado aos funcionários privados (MTESS, 2018).

Chile e Uruguai apresentam as maiores coberturas da América Latina, segundo o OECD (2015), devido às melhores rendas no padrão regional, entretanto esse percentual é baixo se analisado em escala mundial. Esses dois países têm mantido os níveis de cobertura desde a década de 90 , com dificuldades na ampliação dos segurados.

Estudo de Bosch, Melguizo e Pagés (2013) apontou que a aposentadoria, por exemplo, contribui com a redução de desigualdades e da pobreza, especialmente no Uruguai, no Brasil e na Argentina. Precisa integrar políticas contributivas e não contributivas para que amplie a cobertura e o acesso à proteção social.

\section{O SISTEMA NÃO CONTRIBUTIVO: Focalização na Pobreza}

A proteção social desenvolvida pelo Estado capitalista opera na tensão entre seguro e assistência social. Os destinatários do sistema contributivo são aqueles que estão inseridos no mercado de trabalho formal, enquanto os beneficiários do sistema não contributivo são, prioritariamente, os trabalhadores que estão na informalidade e no desemprego, a população idosa, crianças, gestantes e pessoas com deficiência em situação de pobreza. ${ }^{6}$

Na perspectiva neoliberal os benefícios sociais não devem desestimular o trabalho, garantindo a disponibilidade de mão de obra para o capital, por isso os benefícios não contributivos tendem a ter menor valor do que os contributivos. Inclusive o valor deve estar desvinculado do salário mínimo nacional e ser focalizado naqueles que não possuem renda ou vivem na extrema pobreza.

\footnotetext{
4 A heterogeneidade marca os sistemas de seguro social da América Latina, não havendo um modelo único. Após a década de 80 vários países realizam reformas em seus sistemas, visando à retração estatal e à ampliação do setor privado. Em alguns países a participação privada passou a ser predominante (exemplo do Chile), ou outros de forma complementar ou concorrente (como a Argentina e o Uruguai), e em outros a predominância é pública (como o Brasil).

5 Apenas a Argentina possui os dados de 2010, os demais países estão com dados de 2018.

6 Dados da Cepal-OPS (2020) indicam que 54\% da população entre 15 e 59 anos da América Latina estão na informalidade e 8,1\% em situação de desemprego. A pobreza afeta mais a infância, as mulheres e idosos. Estima-se ainda que $12 \%$ da população da região possua alguma deficiência.
} 
A focalização distingue os "merecedores" da atenção pública e aqueles que não correspondem aos objetivos dos programas e das instituições, estigmatizando os pobres e culpabilizando-os pela situação de pobreza. Há ainda um caráter fiscalizador do Estado ao colocar os beneficiários como possíveis "fraudadores" das regras dos benefícios sociais.

Entre os elementos que explicam a persistente situação de pobreza da maioria da população latino-americana está o fato de que as sociedades periféricas não conseguem estabelecer padrões de desenvolvimento e de acesso à renda e ao consumo como os países centrais. Este fato deve-se à concorrência desigual no mercado mundial, que exige um processo de superexploração da força de trabalho para garantir a acumulação capitalista, o que só é possível com rebaixamento salarial e níveis altos de desemprego e informalidade (ARAUJO, 2018).

A questão social expressa-se, principalmente, na superexploração do trabalho e na situação de pobreza de grande contingente da população da região. A pobreza não está relacionada apenas com a renda, mas ao acesso à educação, à saúde, ao saneamento básico, à cultura, ao esporte, à participação social, entre outros elementos indispensáveis para a sociabilidade humana.

A Cepal (2020) destaca que a pobreza afeta mais indígenas e afrodescendentes, os quais correspondem a $10 \%$ e $21 \%$ da população da América Latina, respectivamente, e vivem em piores condições socioeconômicas, possuem mais dificuldades de acesso à proteção social e ao mercado de trabalho comparados com o restante da população. A pobreza atinge mais as crianças e adolescentes (menores de 15 anos), as mulheres e a população rural.

A questão social também se manifesta no processo de luta social e reivindicações dos/as trabalhadores/ as pelo acesso à riqueza socialmente produzida. Segundo Araujo (2018), é o apassivamento via repressão e/ou via cooptação das lutas sociais na região pela burguesia e pelo Estado capitalista que coloca limites à garantia de direitos sociais.

A pobreza está vinculada com a desigualdade social, uma vez que a América Latina é a região mais desigual do mundo (CEPAL-OPS, 2020). Os $10 \%$ mais ricos concentram $37 \%$ da riqueza e os $40 \%$ mais pobres recebem apenas $13 \%$ da riqueza, segundo dados do Programa das Nações Unidas para o Desenvolvimento (PNUD, 2019).

O Quadro 2 expõe os dados de pobreza, extrema pobreza e índice Gini ${ }^{7}$ dos países do Cone Sul.

Quadro 2 - Pobreza, Extrema Pobreza e Gini nos países do Cone Sul da América Latina em $2018^{8}$

\begin{tabular}{|c|c|c|c|c|c|}
\hline País & Argentina & Brasil & Chile & Uruguai & Paraguai \\
\hline Situação de Pobreza & $24,4 \%$ & $19,4 \%$ & $10,7 \%$ & $2,9 \%$ & $19,5 \%$ \\
\hline Situação de Extrema Pobreza & $3,6 \%$ & $5,4 \%$ & $1,4 \%$ & $0,1 \%$ & $6,5 \%$ \\
\hline Índice Gini & 0,41 & 0,54 & 0,45 & 0,39 & 0,47 \\
\hline
\end{tabular}

Fonte: CEPALSTAT (2020).

O Uruguai e o Chile têm os menores indicadores de pobreza e desigualdade da região, o que pode ser relacionado com melhores rendas e coberturas do seguro social, assim como serem pioneiros nas medidas de proteção social pública, como referido anteriormente. Já o Brasil e o Paraguai têm piores índices de pobreza e desigualdade, com o Brasil destacando-se em âmbito regional como o mais desigual.

Cecchini, Filgueira e Robles (2014) ao realizarem um estudo comparado na região, utilizando indicadores sobre o mercado de trabalho, dados demográficos, acesso à educação e saúde e PIB per capita, classificam o Paraguai como um dos países com brechas severas de proteção social, enquanto Argentina, Brasil, Chile e Uruguai estão do lado oposto, como países com brecha moderada.

\footnotetext{
7 O coeficiente de Gini, indicador que mede a desigualdade, varia entre 0 e 1 e, quanto mais elevado, maior a desigualdade registrada.

8 Apenas os dados do Chile são de 2017, os demais são dados de 2018.
} 
A valorização do salário mínimo e as transferências de renda são colocadas como indutores da diminuição da desigualdade social e da pobreza. Precisam integrar, articular e mobilizar, contudo, diferentes políticas sociais, ofertando serviços básicos que garantam a autonomia às famílias, especialmente às mulheres, que são colocadas como as principais responsáveis pelo bem-estar do grupo familiar.

Na América Latina a família tem sido, historicamente, o principal pilar de proteção social, o que pode ser constatado pelo formato dos benefícios não contributivos que têm as famílias (e não os indivíduos) como público-alvo, e o Estado apenas transfere renda se estas não tiverem condições de manter seus membros.

Destaca-se ainda a participação da comunidade na proteção social por meio de redes de solidariedade informal, por exemplo, vizinhança, grupo de mulheres e grupos religiosos e Organizações Não Governamentais - ONGs - formalmente instituídas, com práticas voluntaristas e clientelistas, desenvolvidas com apoio do poder público, via isenção de impostos ou incentivos monetários.

O enfoque neoliberal de combate à pobreza via transferência condicionada de renda também favorece o mercado pela financeirização da política social em duas vias: o pagamento realizado à instituição bancária pela intermediação no acesso ao benefício pela população por número de beneficiários e a cidadania sendo acessada via consumo, o que desvincula a proteção social do direito social devido pelo Estado (ARAUJO, 2018).

A contradição dos programas de transferência condicionada de renda está no fato de um lado atender a uma necessidade imediata da população que necessita desses recursos para sobreviver, contribuir com a redução do trabalho infantil e ao acesso à renda pelas mulheres. E, de outro, desvincular a discussão da pobreza de suas múltiplas determinações e dos elementos estruturais de desigualdade econômica e social das sociedades latino-americanas.

O sistema não contributivo é financiado por impostos que incidem sobre o consumo, pois são regressivos e indiretos, por isso recaem sobre os mais pobres. Deveriam voltar-se a atender às necessidades sociais da população, ofertando serviços públicos e universais de qualidade e garantindo benefícios sociais no valor do salário mínimo nacional.

O Quadro 3 reúne informações sobre os Programas Condicionados de Transferência de renda dos países do Cone Sul, no qual observa-se os destinatários, o valor do benefício (em dólar) e a cobertura (\%).

Quadro 3 - Programas Condicionados de Transferência de Renda no Cone Sul da América Latina em 2018

\begin{tabular}{|c|c|c|c|c|}
\hline País & Programa & Destinatários & Valor (US\$) & Cobertura \\
\hline \multirow[t]{2}{*}{ Argentina } & $\begin{array}{c}\text { Asignación Universal } \\
\text { por Hijo para } \\
\text { Protección Social } \\
(2009-)\end{array}$ & $\begin{array}{l}\text { Famílias com pessoas menores de } 18 \text { anos } \\
\text { ou com deficiências. Mulheres grávidas } \\
\text { desempregadas ou no trabalho informal. } \\
\text { Empregados domésticos com renda menor que } \\
1 \text { salário mínimo e monotributistas sociais. }\end{array}$ & $\begin{array}{l}\text { Entre } 64,6 \text { e } \\
1400,0\end{array}$ & $26,68 \%$ \\
\hline & $\begin{array}{c}\text { Programa de } \\
\text { Ciudadanía Porteña } \\
(2005-)\end{array}$ & $\begin{array}{l}\text { Residentes em Buenos Aires em situação de } \\
\text { pobreza. }\end{array}$ & $\begin{array}{l}\text { Entre } 12,5 \text { e } \\
\quad 612,6\end{array}$ & $0,32 \%$ \\
\hline \multirow[b]{2}{*}{ Brasil } & Programa Bolsa Família & $\begin{array}{l}\text { Famílias em situação de pobreza e extrema } \\
\text { pobreza. }\end{array}$ & $\begin{array}{l}\text { Entre } 5,6 \text { e } \\
\quad 66,30\end{array}$ & $24,83 \%$ \\
\hline & $\begin{array}{c}\text { Programa de } \\
\text { Erradicação do } \\
\text { Trabalho Infantil (Peti) } \\
\text { (1996-) }\end{array}$ & $\begin{array}{l}\text { Famílias pobres com crianças e adolescentes em } \\
\text { situação de trabalho infantil. }\end{array}$ & $\begin{array}{l}\text { Entre } 7,9 \text { e } \\
\qquad 12,7\end{array}$ & $0,05 \%$ \\
\hline \multirow{2}{*}{ Chile } & \begin{tabular}{|l|} 
Chile Seguridades y \\
Oportunidades (2012-)
\end{tabular} & Famílias em situação de extrema pobreza. & Entre 48 e 79 & $4,44 \%$ \\
\hline & $\begin{array}{c}\text { Subsidio Único Familiar } \\
(1981-)\end{array}$ & $\begin{array}{l}\text { Pessoas menores de } 18 \text { anos, mulheres grávidas, } \\
\text { mulheres com filhos, pessoas com deficiência. }\end{array}$ & 35,4 & $19,00 \%$ \\
\hline \multirow[b]{2}{*}{ Paraguai } & Abrazo (2005-) & Famílias com situação de trabalho infantil. & $\begin{array}{l}\text { Entre } 5,69 \\
\quad \text { e } 96\end{array}$ & $0,15 \%$ \\
\hline & Tekoporâ (2005-) & $\begin{array}{l}\text { Famílias em situação de extrema pobreza, } \\
\text { mulheres grávidas, famílias monoparentais com } \\
\text { crianças, pessoas com deficiência, indígenas. }\end{array}$ & $\begin{array}{c}\text { Entre } 4 \text { e } \\
102,9\end{array}$ & $12,21 \%$ \\
\hline
\end{tabular}




\begin{tabular}{|c|c|l|c|c|}
\hline \multirow{4}{*}{ Uruguai } & $\begin{array}{c}\text { Asignaciones } \\
\text { Familiares (2008-) }\end{array}$ & Famílias em situação de pobreza & $\begin{array}{c}\text { Entre 48,7 e } \\
340,9\end{array}$ & $18,46 \%$ \\
\cline { 2 - 5 } & $\begin{array}{c}\text { Tarjeta Uruguay Social } \\
\text { (2006-) }\end{array}$ & $\begin{array}{l}\text { Famílias em situação de extrema pobreza } \\
\text { e pessoas trans (transexuales, travestis e e } \\
\text { transgénero). }\end{array}$ & $\begin{array}{c}\text { Entre 32,3 e } \\
173,6\end{array}$ & $12,04 \%$ \\
\hline
\end{tabular}

Fonte: CEPAL (2020) Base de datos de programas de protección social no contributiva en América Latina y el Caribe.

Os Programas são voltados aos grupos familiares em situação de pobreza, com valores variáveis conforme a composição familiar. Observa-se, contudo, que são valores baixos, desvinculados do salário mínimo nacional e de baixa cobertura, se considerarmos que mais da metade da população da região encontra-se em situação de informalidade.

O Estado uruguaio tem avançado na aproximação com as pautas progressistas, em especial com a discussão sobre a igualdade de gênero, a legalização do abordo, o respeito à diversidade, a legalização da maconha. Esse debate tem impulsionado outros países na região. Destaca-se que essa aproximação com pautas progressistas reflete-se na inclusão de pessoas trans (transexuais, travestis e transgêneros) em situação de pobreza como público-alvo do Programa Tarjeta Social.

As condicionalidades dos programas de transferência de renda, de modo geral, estão voltadas ao acesso às políticas sociais de educação (frequência e aproveitamento escolar) e de saúde (vacinação, acompanhamento prenatal), direitos sociais básicos que devem ser garantidos pelo Estado. As penalidades ao descumprimento são progressivas, da suspensão ao cancelamento do benefício.

Destaca-se, conforme Araujo (2018), a influência do economista indiano Amartya Sen, o qual defende que a simples redistribuição é prejudicial ao mercado, por isso as condicionalidades investem no "empoderamento" individual, na habilitação e na capacitação dos mais pobres para ingresso no mercado de trabalho, o que reatualiza a moralização e individualização da situação de pobreza.

Além dos programas condicionados de renda, os países da região do Cone Sul possuem benefícios não contributivos voltados a idosos e pessoas com deficiência que não possuem seguro social e estão em situação de pobreza, conforme o Quadro 4:

Quadro 4 - Benefícios não contributivos no Cone Sul da América Latina em 2018

\begin{tabular}{|c|c|c|c|c|}
\hline País & Benefício & Público-alvo & $\begin{array}{l}\text { Valor } \\
\text { (US\$) }\end{array}$ & $\begin{array}{l}\text { Cobertura (no. } \\
\text { beneficiários) }\end{array}$ \\
\hline \multirow[t]{2}{*}{ Argentina } & $\begin{array}{l}\text { Pensión Universal para el } \\
\text { Adulto Mayor (2016-) }\end{array}$ & Maiores de 65 anos. & 269,96 & 115.377 \\
\hline & $\begin{array}{l}\text { Programa de Pensiones no } \\
\text { Contributivas (1948-) }\end{array}$ & $\begin{array}{l}\text { Maiores de } 70 \text { anos; Mulheres com } 7 \text { ou } \\
\text { mais filhos vivos; Pessoas com deficiência; } \\
\text { Pessoas beneficiárias por leis especiais. }\end{array}$ & $\begin{array}{l}\text { Entre } \\
231,9 \text { e } \\
312,1\end{array}$ & 1.420 .438 \\
\hline \multirow[t]{2}{*}{ Brasil } & $\begin{array}{l}\text { Benefício de Prestação } \\
\text { Continuada (1996-) }\end{array}$ & $\begin{array}{l}\text { Maiores de } 65 \text { anos e pessoas com deficiência } \\
\text { em extrema pobreza. }\end{array}$ & 261,1 & 4.651 .924 \\
\hline & Previdência Rural (1993-) & $\begin{array}{l}\text { Pessoas residentes em área rural ou urbanas } \\
\text { de até } 50.000 \text { habitantes com desempenho } \\
\text { econômico em área rural ou pesca artesanal. } \\
\text { Pessoas com deficiência que vivem na área } \\
\text { rural. }\end{array}$ & 261,1 & 6.957 .148 \\
\hline Chile & $\begin{array}{l}\text { Pensión Básica Solidaria } \\
\text { (ex-Pasis) (2008-) }\end{array}$ & $\begin{array}{l}\text { Maiores de } 65 \text { anos e pessoas com deficiência } \\
\text { entre } 18 \text { e } 65 \text { anos em situação de pobreza. }\end{array}$ & 494,5 & 585.212 \\
\hline Paraguai & $\begin{array}{c}\text { Pensión Alimentaria } \\
\text { Para Adultos Mayores en } \\
\text { Situación de Pobreza (2009- }\end{array}$ & Maiores de 65 anos em situação de pobreza. & 92,1 & 191.995 \\
\hline Uruguai & $\begin{array}{l}\text { Pensiones no contributivas } \\
\text { por vejez e invalidez (1919-) }\end{array}$ & $\begin{array}{l}\text { Maiores de } 70 \text { anos ou pessoas com } \\
\text { deficiência. }\end{array}$ & 329,6 & 84.783 \\
\hline
\end{tabular}

Fonte: CEPAL (2020) Base de datos de programas de protección social no contributiva en América Latina y el Caribe. 
Os benefícios sociais destinados a idosos e pessoas com deficiência, no valor de um salário mínimo nacional, poderiam impactar ainda mais na diminuição da situação de pobreza desses grupos e da desigualdade social na região se estivessem vinculados à lógica social, como direito de todos os/as idosos e pessoas com deficiência, independentemente da comprovação da insuficiência de renda, tendo em vista que o atual formato destina-se aos comprovadamente pobres.

A relação dos dados sobre a situação de pobreza, benefícios contributivos e não contributivos apresentam um panorama da proteção social no Cone Sul da América Latina. Constata-se diferenças significativas entre os países, estando Paraguai e Uruguai em lados opostos, o que revela a necessidade de uma análise histórico-social de cada país para identificar os trajetórias e os principais desafios de se romper com a lógica do seguro na proteção social pública, visando a sua universalização e a construção de sistemas de proteção social a partir da realidade local.

\section{CONSIDERAÇÕES FINAIS}

Os modelos de proteção social pública adotados pelo Cone Sul da América Latina desde o século 20 têm como referência as experiências europeias e vinculam-se à organização social do trabalho assalariado. Os limites desses sistemas têm sido objeto de problematização das sociedades, principalmente em relação ao acesso, aos valores e à cobertura.

O mercado de trabalho instável (grande rotatividade de profissionais, de empresas pequenas que não se mantêm, entre outros elementos), a crescente informalidade e desemprego são aspectos que tencionam a proteção social pública, que precisa ser repensada à luz das necessidades sociais da população.

Neste processo, o revisionismo histórico é importante para se compreender os limites do Estado capitalista na região para garantir a proteção social pública, assim como as dívidas com os povos originários e africanos que precisam ser sanadas por meio de políticas de proteção social, políticas afirmativas e políticas de valorização cultural, devido ao permanente extermínio desses povos.

Destacam-se dois elementos da questão social: a primeira é a superexploração do trabalho e, consequentemente, a situação de pobreza da população e a segunda, a forma clientelista e de cooptação das lutas sociais, assim como a antecipação de suas reivindicações. Resultado desse processo de luta social e resistência são os sistemas contributivos e não contributivos que estão sendo desenvolvidos.

Os países do Cone Sul - Argentina, Brasil, Chile, Uruguai e Paraguai - possuem questões em comum devido ao colonialismo, mas, entre si, grande diversidade. Os dados apresentados sobre os benefícios e programas sociais desenvolvidos pelos países exigem o aprofundamento na análise histórico-social de cada sociedade e a realização de novas pesquisas para explicar os principais desafios de cada país.

Por fim, destaca-se que a redistribuição da riqueza socialmente produzida por meio da valorização do salário mínimo e dos benefícios sociais é um dos mecanismos que pode contribuir para a diminuição da pobreza e da desigualdade social na região, mas precisa estar combinada com reformas estruturais, como a forma de arrecadação.

Compreende-se também que o atual formato da proteção social pública não está sendo capaz de atender às necessidades da população porque está desvinculada da questão econômica e política, atuando em questões emergenciais. Torna-se urgente debater socialmente a atual ação estatal no Cone Sul da América Latina.

\section{REFERÊNCIAS}

ALMEIDA, Silvio Luiz de. Racismo estrutural. São Paulo: Pólen, 2019.

ARAUJO, Ricardo Souza. Financeirização e focalização da Assistência Social na América Latina: um debate sobre os Programas de Transferência de Renda. JORNADAS BOLIVARIANAS, 14., 2018. Florianópolis: UFSC; Instituto de Estudos Latino-Americanos - lela, 2018.

BOSCH, Mariano; MELGUIZO, Ángel; PAGÉS, Carmen. Melhores aposentadorias melhores trabalhos em direção à cobertura universal na América Latina e no Caribe. Washington: Banco Interamericano de Desenvolvimento, 2013.

BOSCHETTI, Ivanete. Seguridade Social no Brasil: conquistas e limites à sua efetivação. In: CFESS - Conselho Federal de Serviço Social. Serviço Social: direitos sociais e competências profissionais. Brasília: Cead; UnB, 2009. p. 323-340. 
CECCHINI, Simone; FILGUEIRA, Fernando; ROBLES, Claudia. Sistemas de protección social en América Latina y el Caribe: una perspectiva comparada. Santiago, Chile: Cepal, 2014. (Série Políticas Sociales, $\mathrm{n}^{\circ} 202$ ).

CEPAL. Comissão Econômica para América Latina e Caribe. Base de datos de programas de protección social no contributiva en América Latina y el Caribe. Disponível em: https://dds.cepal.org/bpsnc/acerca?bd=ilp. Acesso em: 25 ago. 2020.

CEPAL. Comissão Econômica para América Latina e Caribe. Panorama Social da América Latina 2018. Documento informativo. Santiago: Cepal, 2019.

CEPALSTAT. Comissão Econômica para América Latina e Caribe/Estatística. Bases de Datos y Publicaciones Estadísticas. Disponível em: https://estadisticas.cepal.org/cepalstat/portada.html. Acesso em: 25 ago. 2020.

CEPAL-OPS. Comissão Econômica para América Latina e Caribe e Organização Panamericana de Saúde. Informe Covid-19: Salud y economía: una convergencia necesaria para enfrentar el Covid-19 y retomar la senda hacia el desarrollo sostenible en América Latina y el Caribe. Santiago: Cepal, jul. 2020.

DRAIBE, Sônia M.; RIESCO, Manuel. Estados de Bem-Estar Social e estratégias de desenvolvimento na América Latina. Um novo desenvolvimentismo em gestação? Dossiê Sociologias, Porto Alegre, a. 13, n. 27, p. 220-254, maio/ago. 2011.

IBGE. Instituto Brasileiro de Geografia e Estatística. Pesquisa Nacional Por Amostra de Domicílios. Fev. 2020.

LUGONES, María. Rumo a um feminismo descolonial. Estudos Feministas, Florianópolis, p. 935-952, set./dez. 2014.

MESA-LAGO, Carmelo. As reformas de previdência na América Latina e seus impactos nos princípios de seguridade social. Trad. Secretaria de Políticas de Previdência Social. Brasília: Ministério da Previdência Social, 2006.

MONTAÑO, Carlos. Pobreza, "questão social" e seu enfrentamento. Revista Serviço Social e Sociedade, n. 110, São Paulo: abr./ jun. 2012, p. 270-287.

MTESS. Ministerio de Trabajo, Empleo y Seguridad Social. Boletín Estadístico de Seguridad Social. Asunción, Paraguay: MTESS, 2018.

OECD. Organização para Cooperação e Desenvolvimento Econômico. Um panorama dos sistemas previdenciários na América Latina e no Caribe. Brasília, DF: OECD, Banco Mundial, BID, 2015.

PNUD. Programa das Nações Unidas para o Desenvolvimento. Relatório do Desenvolvimento Humano. New York: PNUD, 2019. QUIJANO, Anibal. Colonialidade do poder, eurocentrismo e América Latina. In: LANDER, Edgardo (org.). A colonialidade do saber: eurocentrismo e ciências sociais. Perspectivas latino-americanas. Ciudad Autónoma de Buenos Aires, Argentina: Clacso, set. 2005. p. 227-278. (Colección Sur Sur).

ROUQUIÉ, Alain. O Estado Militar na América Latina. São Paulo: Editora Alfa-Omega, 1982.

SILVA, Sidney Jard da. Novos modelos previdenciários na América Latina: lições da experiência Argentina. Revista de Economia Política, v. 28, n. 2, p. 312-330, abr./jun. 2008. 